\title{
Las líneas: elementos determinantes de la investigación
}

\author{
Omar Parra Rozo*
}

Recibido: 2 de febrero de 2009 Revisado: 17 de abril de 2009 Aprobado: 4 de abril de 2009

\section{Resumen}

Como el trazo esencial que da figura y origen a lo existente, desde sus orígenes míticos hasta los razonamientos científicos y desde el diario transcurrir hasta las formas estéticas que de ella se derivan, la línea es el elemento constitutivo que proporciona sentido, horizonte y razón al conocimiento y al sentir humano. Los múltiples problemas que se originan en el contexto que rodea un hecho cotidiano, un experimento o una reflexión filosófica, un acto de fe o un asunto pedagógico, suscitan un planteamiento de propuestas y proyectos. La construcción y la reconstrucción de éstos, el esbozo metodológico, los procesos y los productos investigativos, su socialización y difusión tienen una raíz esencial: la línea que los origina. A partir del mito y la narrativa se consigue vislumbrar la génesis de la línea y su armazón determinante en el progreso del conocimiento, la docencia y la investigación. Se puede decir, merced a lo investigado, que se mantiene un descuido epistemológico en la explicación de la línea de conocimiento o de investigación que debe ser subsanado yendo a sus orígenes y visualizando su prospectiva, pues la línea constituye un referente imprescindible y estructural de cualquier proceso investigativo.

\section{Palabras clave}

Líneas, punto, narrativa, mito, ciencia, arte, líneas institucionales, objeto, problemas.

* Doctor en Literatura. Magíster en Administración Educativa y Licenciado en Filología y Literatura. Líder de dos grupos de investigación reconocidos por Colciencias: Relaciones, redes y narrativas (categoría A), Gestión, investigación y narrativa (categoría B). Correo electrónico: omarparra@ usantotomas.edu.co. 


\title{
Lines: determined elements of investigation
}

\author{
Omar Parra Rozo
}

\begin{abstract}
As the essential outline that gives figure and origin to the existing thing, from its mythical origins to the scientific reasonings and from the daily living to the aesthetic forms which are derived from them, line is the constituent element that provides sense, horizon and reason to the knowledge and the human feeling. The multiple problems that are originated in the context that surrounds a daily fact, an experiment or a philosophical reflection, an act of faith or a pedagogical subject, provoke an exposition of proposals and projects. The construction and the reconstruction of the same, the methodologic outline, the research processes and products, their socialization and diffusion have an essential root: the line that originates them. From myth and narrative fiction it is able to glimpse the genesis of the line and its determining frame in the progress of knowledge, teaching and investigation. It is possible to say, thanks to the investigated thing, that stays an epistemological negligence in the explanation of the line of knowledge or investigation that must be corrected going to its origins and visualizing its forecast, because the line constitutes an essential and structural referent of any research process.
\end{abstract}

\section{Key words}

Lines, point, narrative, myth, science, art, Institutional lines, object, problems.

Recibido: 2 de febrero de 2009 Revisado: 17 de abril de 2009 Aprobado: 4 de abril de 2009 
Las líneas principales guían al espectador dentro de la composición, lo llevan hacia el punto de enfoque y le hacen ver los diferentes elementos.

\section{Brenda Hoddinott}

\section{Preludio}

El presente artículo es un producto terminal del macroproyecto investigativo institucional Proin: Gestión investigación y narrativa²

1 Brenda Hoddinott es una artista canadiense que se ha dedicado a la ilustración, la ciencia forense y el dibujo. Profesora de arte en diversos niveles, combinó su tendencia estética con la práctica criminalística, obteniendo menciones y distinciones en esta área. Su tarea pedagógica y profesional la ha llevado a profundizar en la elaboración de diseños, dibujos y pinturas. Su inquietud por enseñar su método de acercamiento e interpretación de la realidad la encaminó a crear Hodinott Fine Art y los sitios web: www.hodinott.com y www.finearteducation.com. Su libro Dibujo para Dummies ha tenido gran aceptación entre los aprendices del dibujo por sus contenidos, los cuales brindan herramientas y conceptos sencillos que guían al futuro dibujante. La líneas las concibe como el elemento básico y determinante para ver la realidad: "Es cierto que una línea recta sólo se puede dibujar en tres sentidos: horizontal, vertical y diagonal, pero se puede lograr mucho con estos tres sentidos" (Hoddinott, s.f., p. 63).

2 Tanto en el grupo de investigación Relaciones, redes y narrativas como en el grupo Gestión, investigación y narrativa se trabajan sendos proyectos investigativos que intentan ver los aportes que brindan al proceso de investigación las diversas disciplinas y temas del conocimiento, apuntando a una combinación entre lo científico, lo artístico y lo "humano". La desmitificación de un proceso no implica que se demerite éste o se desgaste, por el contrario, se busca el enriquecimiento desde otros puntos de vista y se trata de encontrar la esencia investigativa, propiamente dicha, tanto en el diario transcurrir, como en el más complejo proceso investigativo y tanto en los intrincados vericuetos científicos, como en las ingenuos y creativos juegos, cantos y cuentos infantiles. Los cuatro primeros productos del macroproyecto Proin (Proyecto investigativo institucional): Gestión, investigación y narrativa, al igual que los productos sexto, séptimo, octavo y noveno, se pueden consultar en los siguientes números de la Revista de investigaciones Hallazgos, de la Universidad Santo Tomás: No. 2, La gestión es cosa de niños (2004); No. 4, Gestión, investigación y narrativa: La investigación es un cuento de hadas (2005); No. 5, Gestión, investigación y narrativa: investigar es un juego (2006); №. 6, Investigación, docencia y tecnología (2006); No. 7, Investigar: leer y escribir, No. 8, Pinocho: ¿aprendiz de investigador? (2007); No. 9, El tiempo: secreto de la investigación (2008) y No. 10, Investigación, ciencia, tecnología ¿ver o no ver? (2008) El quinto producto investigativo se puede y responde a la problemática de la génesis, la definición y la prospectiva de las líneas, que constituyen un elemento ineludible en el proceso investigativo y del conocimiento. La búsqueda de la verdad, los proyectos, los problemas, las políticas investigativas, los marcos académicos, los grupos de investigación, los semilleros y los investigadores caminan por el filo de la línea, se contornean a su ritmo. El fundamento de lo investigado y la estructura del conocimiento tienen una base en las líneas, las cuales les dan sentido y dirección.

En el Diccionario de la Real Academia Española se suelen encontrar múltiples definiciones para la línea, las cuales van desde su primigenia acepción: sucesión continua e indefinida de puntos en la sola dimensión de la longitud, hasta su aplicación como "tirar línea", referido a escribir. Tratar de encontrar un calificativo, una descripción o un significado para el término línea constituye una tarea ardua, esto sin tomar en cuenta las metáforas que llevan a diversos y variados significados como la línea infinita de tu mirada, la línea que limita tus sentimientos o la línea interminable de tu pensamiento, alegorías inagotables que, aún sin entrar en los vericuetos de las líneas calientes, las líneas de la droga o las líneas del desenfreno, nos regresan a la génesis, a las líneas que existen en el trasfondo de cada actividad humana, desde las mismas formas armoniosas de un cuerpo, hasta la línea aerodinámica de un cohete espacial, la línea de una discusión o la línea de acuerdo, la llegada a la línea o estar detrás o delante de ella. El orden formal en el deporte o en la milicia y aun la desconcertante línea de un juego de bingo,

consultar en el artículo La investigación es un placer (2007) publicado por la Revista Aquichán de la Facultad de Enfermería, Universidad de La Sabana (Año 7, Vol.7, No. 111-112). 
de ajedrez o de fútbol reiteran la concepción de línea unida al ser humano que, de igual manera, se manifiesta en la línea musical o la línea que prefija un cuadro o una pintura.

El más intrincado laberinto de cadenas que conforman la línea genética y la línea del espiral del ADN recuerdan al hombre su complejidad y lo obligan a mirar su interior tanto como lo que se halla afuera: la línea de agua y la del orden de la batalla, la que marca la longitud y la latitud, la que se pierde en la lejanía y la que limita el horizonte, la de la vida y la de la eternidad. Interminables clases de líneas que se vuelven infinitas, merced a su combinación, líneas que conforman un plano y un sólido, una figura, un cuerpo, un espacio y un tiempo. Definitivamente, la línea que divide y la que une, la que da consistencia y la inestable.

\section{GÉNESIS MíticA Y NARRATIVA}

Los mitos necesariamente tocan la concepción de líneas, desde la idea de la geometría que se inserta en un imaginario colectivo para plantear que la Tierra es plana, cilíndrica, esférica o con alguna forma que supone un polígono. Al buscar la génesis de lo creado se puede efectuar una inserción en las narraciones maravillosas occidentales o volver la mirada al pensamiento mítico oriental. En este último marco, una alegoría popular china sobre el origen del mundo hace recordar que "en el principio era el huevo...", a partir del cual se generó lo existente. En el huevo se hallaban las fuerzas contrarias, lo femenino y lo masculino, la tierra y el cielo, la luna y el sol y otros atributos que condensaban el Yin y el Yang. De la lucha eterna de estas dos fuerzas surgió lo existente: la naturaleza con todos sus seres, los dioses y los hombres.
Una de las divinidades, $\mathrm{Fuxi}^{3}$, señor del trueno, según muchos creyentes, fue el encargado de entregar el fuego y el conocimiento a los hombres; uno de los atributos del dios, el de la escritura, le fue transmitido a los seres humanos, quienes, desde entonces, se comunican a través de líneas e ideogramas, símbolos con los que se recrean los individuos, las ideas y las cosas. Los habitantes de la Tierra también recibieron el $I$ Ching, un referente milenario que pretende que su lector y practicante tenga un profundo estudio "de sí mismo, de su interioridad, de la cual procede toda respuesta válida y también toda apertura hacia nuevas indagaciones" (Wilhem, 1982, p. 10).

Las enseñanzas y los mensajes contenidos en este texto se inspiran en la naturaleza y, al igual que en la concepción presocrática, intentan mostrar que lo creado obedece a la existencia de los elementos primordiales, en el caso chino: el fuego, el lago, el viento, la madera, la montaña, el agua, el trueno, la tierra y el cielo. El libro sagrado contiene una dosis elevada de moral y filosofía y se constituyó, a lo largo de los siglos, en un material de consulta para el comportamiento en la vida. Su estructura es aritmética y geométrica, en el sentido estricto de los componentes, cuya escritura, extrañamente, se realiza con líneas continuas que constituyen los números impares y líneas quebradas que representan los pares. El trazo de tres líneas sobre un papel constituye un trigrama; los

3 En la Introducción al I Ching, al hacer referencia a la historia del tratado, se alude a "cuatro santos como autores del Libro de las mutaciones: Fu Hi, el rey Wen, el Duque de Chou y Kung Tse (Confucio)" (Wilhem: 71). La construcción de este legado moral se refunde en el tiempo y se habla de su aparición hacia el 2400 a.C. Por un extraño paralelismo, en la cultura occidental, el dios del trueno, Zeus, también es el dios de la sabiduría, del conocimiento y la inteligencia. Se alude al origen mítico chino por acudir a una cultura que tiene su esencia expresiva en el grafismo, en la pintura y en la combinación infinita de las líneas. 
trigramas básicos en este lenguaje son ocho y tienen significados que asocian el nombre con una cualidad, una imagen y una familia: lo receptivo, lo creativo, lo sereno, en- tre otros, tal y como se puede apreciar en el cuadro explicativo que Richard Whilhem plantea en la Introducción al I Ching (1982, p. 63):

\begin{tabular}{|c|c|c|c|c|c|c|}
\hline \multicolumn{4}{|l|}{ Nombre } & \multirow{2}{*}{$\begin{array}{l}\text { Cualidad } \\
\text { Fuerte }\end{array}$} & \multirow{2}{*}{$\begin{array}{l}\text { Imagen } \\
\text { Cielo }\end{array}$} & \multirow{2}{*}{$\begin{array}{l}\text { Familia } \\
\text { Padre }\end{array}$} \\
\hline 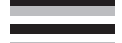 & Ch'ien & Kien & lo Creativo & & & \\
\hline 믈 & K'un & Kun & lo Receptivo & Abnegado & Tierra & Madre \\
\hline 므믐 & Chen & Dschen & lo Suscitativo & Movilizante & Trueno & 1er. hijo \\
\hline 2 & $K^{\prime} a n$ & Kan & lo Abismal & Peligroso & Agua & $2^{\underline{o}}$ hijo \\
\hline 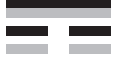 & Ken & Gen & el Aquietamiento & Quieto & Montaña & 3er. hijo \\
\hline$=$ & Sun & Sun & lo Suave & Penetrante & Viento, Madera & $1^{\mathrm{a}}$ hija \\
\hline$=$ & $\mathrm{Li}$ & $\mathrm{Li}$ & lo Adherente & Luminoso & Fuego & $2^{\mathrm{a}}$ hija \\
\hline$=$ & Tui & Dui & lo Sereno & Regocijante & Lago & $3^{\mathrm{a}}$ hija \\
\hline
\end{tabular}

De la combinación de los ocho trigramas derivaron 64 hexagramas, conocidos hoy en día como la base del libro. Se resalta que las líneas constituyen la base del conocimiento; sin ellas no se es, no se existe. Las líneas constituyen el fundamento de lo que fue, de lo que es y de lo que será, en todas las fases de la vida, de actuar, de ser, de sentir y de creer. En las líneas están dadas las razones de la búsqueda y del cuestionamiento; una frase en la presentación del libro, fundamenta el quehacer investigativo y la razón de cualquier proyecto: "toda pregunta clara lleva en sí misma la respuesta" (Wilhem, 1982, p. 15). El fundamento matemático de las enseñanzas del I Ching fue visto por algunos científicos y escritores diversos como un referente básico del conocimiento: "Ya en 1703 Leibniz ${ }^{4}$ declara su sorpresa frente

4 Gottried Wilhelm von Leibniz. (1646-1716), a juicio de los estudiosos, es uno de los más grandes pensadores alemanes: filó- a la total coincidencia matemática de la estructura y ordenamiento de los hexagramas del I Ching con el sistema numérico binario ideado por él (para fines diferentes)" (Wilhem, 1982, p. 14).

sofo, matemático, jurista, político y alquimista. Deambuló por las distintas facetas del conocimiento y, junto a Newton, pero en espacios diferentes, planteó los postulados del cálculo infinitesimal. También insertó diversos aportes en los ámbitos metafísicos, epistemológicos y lógicos. Su teoría de las mónadas es muy considerada en los temas sobre el átomo; su tratamiento sobre el sistema binario tuvo que ser analizado en la construcción del lenguaje computacional. En su texto De Leibniz a la Enciclopedia, Umberto Eco recrea el pensamiento de Leibniz, referido al lenguaje y a la búsqueda de una lengua común, una utopía con la cual el ser humano ha soñado desde siempre. Leibniz quería, más allá de una unión a través del lenguaje matemático y filosófico, una unión religiosa, trascendente: "En la época en la que sus predecesores y coetáneos ingleses están pensando en una lengua universal destinada ante todo a los intercambios comerciales y a los viajes, además del intercambio científico, encontramos, en cambio, en Leibniz un aliento religioso [...]. Pero el modo de llegar a este entendimiento no pasaba para Leibniz, por la creación de una lengua universal. Pasaba más bien por la creación de un lenguaje científico que fuese instrumento útil para el descubrimiento de la verdad" (Eco, 1994, p. 158). 
La influencia palpable de los trazos de este libro se ve en la obra de múltiples científicos y artistas. Jorge Luis Borges con su poema trascendente, Para una versión del I King, abre una de las versiones de El libro de las mutaciones, en el que trata de mostrar la eternidad del lenguaje, probablemente el indescifrable trazado de las líneas, de la escritura:

El porvenir es tan irrevocable Como el rígido ayer. No hay una cosa

Que no sea una letra silenciosa

De la eterna escritura indescifrable

Cuyo libro es el tiempo (Wilhelm, 1982, p. 7).

Por su parte, Umberto Eco, en El I Ching y la numeración binaria, comenta que el matemático Leibniz, en los últimos años de su vida, se dedicó al estudio de la cultura china, en particular a la relación de la matemática con lo trascendente y llegó a conclusiones como que el Libro de las metamorfosis está íntimamente relacionado con las concepciones aritméticas binarias, es decir, el cálculo por 1 y por 0 que, aunque no era el propósito de las enseñanzas de la obra, cuyo mensaje trascendente desborda estas relaciones, no impide que Leibniz vea en los trazados y las líneas de los hexagramas "la perfecta representación de la progresión de los números binarios que, de hecho, se escriben según la secuencia 000, 001, 010, 110, 101..." (Eco, 1994, p. 165). Eco agrega que, aunque Leibniz sólo consideró la forma y la capacidad combinatoria "Nos encontramos de nuevo ante una exaltación del pensamiento ciego, ante un reconocimiento de la forma sintáctica como vehículo de la verdad" (Eco, 1994, p. 166). Las líneas y los trazos que fueron dados para una cultura oriental, distante en concepción y horizonte, encuentran un referente occidental matemático y explicativo, desde Leibniz.
En este punto es importante precisar que Eco, con el referente del matemático alemán, da a entender por pensamiento ciego "la posibilidad de realizar cálculos y llegar a resultados exactos a base de símbolos cuyo significado no se conoce necesariamente, o de cuyo significado no se consigue tener una idea clara y definida". El semiólogo y novelista italiano manifiesta que esta noción, claramente expuesta por Leibniz, es recogida más adelante en la semiótica por Lambert (siglo XVIII) y otros estudiosos del lenguaje, en cuanto hacen referencia a la manipulación de los signos y de los caracteres sin tener claridad de su significado (Eco, 1994, pp. 162-163). Esto último constituye un problema vigente en los procesos de enseñanza y aprendizaje, aun en los procesos investigativos y merece un cuidadoso análisis. El universo de las líneas desborda el lenguaje trascendente, metafórico y se inserta en los rincones del lenguaje preciso, tanto como del lenguaje pedagógico y popular.

Desde el panorama filosófico-psicológico se puede apreciar que el uso de las líneas que se observa en la ciencia, el arte y la vida cotidiana tiene hondas raíces que hacen alusión a diversos tratamientos originales y primarios que tratan de explicar y representar la realidad con modelos, imágenes o esquemas comunes a todos los hombres, esbozos que traspasan el tiempo y el espacio y se constituyen en arquetipos, los cuales reivindican un cosmos imaginario: "un lugar geométrico de los grandes temas, símbolos, figuras y mitos recurrentes" (Marchese \& Forradellas, 1994, p. 37). El I Ching constituye un ejemplo de este universo, con sus líneas y su trasfondo teológico, filosófico, moral, un infinito linear que enmarca la vida. Un caso similar se puede apreciar con el pensamiento matemático de Leibniz, traído a colación 
por Eco o, simplemente, en el mundo que rodea al ser humano y que le brinda una infinita gama de interpretaciones desde el punto sencillo y la línea llana hasta sus intricadas combinaciones.

\section{EL PUNTO COMO REFERENTE DE LA LÍNEA}

Inmediatamente finalizada la Primera Guerra Mundial, un pintor magistral le mostró al mundo la posibilidad infinita de explicar la realidad, no solamente a través del arte, sino también con la ciencia del arte, con la investigación y la reflexión sobre lo que se opone a la estética, pero que puede dar referentes para su interpretación, su asimilación y, particularmente, su sentir y su vivencia: Vasily Vasilievich Kandinsky. Para este artista ruso, el camino de la investigación sólo se puede entender como el procedimiento detallado que comienza con el planteamiento o el examen que se hace de cualquier realidad susceptible de ser estudiada; desarrollo que luego se profundiza en la contrastación, la interacción y la comparación de los acontecimientos entre sí y que, finalmente, en un tercer paso, lleva a la conclusión, la cual, a su vez, se deduce de los dos escalones anteriores:

El proceso ideal de toda investigación consiste:

1. En el minucioso examen de cada fenómeno por separado.

2. En la oposición de los fenómenos entre sí.

3. En las conclusiones generales deducibles de las dos etapas anteriores (Kandinsky, 1994, p. 16).

En otras palabras, todo proceso investigativo, al igual que cualquier abordaje científico o artístico, supone una dialéctica. En este punto se recuerdan los postulados griegos que llevan al hombre a aprender y a com- prender lo que está fuera de él y, por supuesto, la manera de acercarse al conocimiento, tal y como lo manifestarían posteriormente santo Tomás de Aquino y Alberto Magno en los albores del saber sistematizado, en el nacimiento de las universidades del siglo XII, con la forma de acceso al estudio y develar fenómenos que se conocen como el método investigativo-expositivo; estos planteamientos luego llevarían al método científico y a las formas de acercarse a un hecho cualquiera tratando de explicarlo.

Transcurrieron varios siglos hasta que se encontró una manera diferente de acercarse al mundo, de interpretarlo, de investigar acerca de él. La línea que alguna vez fue el simple trazado de un punto a otro, en la actualidad es un elemento definitivo en el ámbito de la investigación. Cada persona tiene que ser un investigador, so pena de no sobrevivir. El simple hecho de enfrentarse a un fenómeno hace que el ser humano indague, haga suyo lo percibido y lo cuestione. En el campo de la pedagogía, que se ocupa de la enseñanza y el aprendizaje, el hecho educativo se constituye en un proceso investigativo, en el cual, tanto la persona que aprende como quien enseña, por separado y luego juntos, tienen que investigar, el uno para perfeccionar su didáctica y el otro para apropiarse y asimilar lo que se le presenta ${ }^{5}$.

5 En los procesos educativos surge una discusión acerca del papel investigativo del profesor: si es o no un investigador. El docente, por la simple naturaleza de su profesión, debe estar en constante evolución y adaptación a los veloces productos científicos que se van insertando en el diario devenir. Un estudiante del presente año es completamente diferente de uno del año inmediatamente anterior. Esto requiere de innovaciones didácticas y de una constante indagación por parte del docente y de la institución educativa. El profesor Bernardo Restrepo Gómez establece una diferenciación entre la investigación formativa y la investigación en sentido estricto (aplicada, científica) que ha sido tomada como referencia en los procesos de autoevaluación, acreditación de programas y acreditación institucional en Colombia. Una investigación que propugna por el estudio de las 
Con el punto suele suceder lo mismo que con la línea: sus múltiples significados confluyen para conformar el sitio de salida o el de llegada, el centro de un polígono o la arista, el círculo o una esfera compleja. Los puntos, al sumarse o encadenarse, dan forma a la línea. Una definición metafórica y real que ayuda a explicar por qué la sucesión de propuestas y proyectos puede llegar a ser un constructo y un elemento sólido en el mundo investigativo.

\section{LÍNEAS Y ESFERAS}

Las líneas se aplican en todos los tratamientos cognitivos, científicos y artísticos, los ejemplos son múltiples y basta nombrar uno para ver la magnitud del concepto, referente a algunas medidas de la Tierra ${ }^{6}$ latitud

prácticas pedagógicas, los métodos, las formas investigativas diarias, la formación investigativa, los inicios y las aplicaciones educativas e investigativas en el aula, en el diario contacto en los grupos primigenios y otra investigación "aplicada" o en sentido estricto, sistemática, precisa, que apunta a la esencia, la investigación en sí misma, su óptica epistemológica, por diseños, validaciones, experimentaciones, e impacto en la sociedad y en el currículo mismo. Restrepo dice que la investigación pedagógica sólo se puede realizar a partir de la claridad teórica que define "los espacios y los objetos de la pedagogía", los cuales son "el método de enseñar y el método de formar, así como las instituciones y sujetos con ellos relacionados". Agrega que la investigación de estos objetos se puede "hacer teórica, experimental y tecnológicamente" (Restrepo, 1997).

6 Las diversas culturas han tratado de mostrar medidas que le ayuden a comprender dónde están situadas, qué pretenden con sus estructura, para dónde van y un sinnúmero de interrogantes. La conformación del suelo donde se encuentra determinado pueblo lo hace visualizar diferentes horizontes: lo que está arriba, lo que se encuentra abajo 0 a los lados, en su interior y fuera de él. Por ejemplo, en Grecia, cuna de la cultura Occidental, los primeros filósofos consideraban la Tierra como una isla rodeada de agua; posteriormente, se pensó que era un cilindro, luego se introdujo la idea de las esferas como componentes del firmamento. El mismo Aristóteles desde su presupuesto de que "la Tierra era imperfecta y estaba en constante cambio mientras que los cuerpos celestes eran eternos y sin mácula, corrigió el modelo para incluir 54 esferas cristalinas que sin duda él aceptaba como reales y no metafóricas" (Hathaway, 2008, p. 40). Por su parte Aristarco de Samos (siglo IV a.C.) calculó las distancias entre la Tierra, el Sol y la Luna, a través de sus conocimientos y longitud. Desde sus definiciones más elementales, se puede considerar, la primera, si se hace referencia a un plano, como aquella extensión menor que tiene una figura en relación con una mayor. Con la geografía como marco, la latitud es aquella distancia, medida en grados de meridiano, desde un punto de la superficie hasta el Ecuador. En la circunferencia terrestre, se parte de la línea del Ecuador o línea cero de latitud, la cual, al extenderse muestra el máximo círculo imaginario que demarca la tierra desde cualquiera de los dos polos y cuyo centro, necesariamente es el centro del planeta. Estas líneas se denominan paralelos, en contraposición a las líneas verticales que los cruzan, denominadas meridianos. Estas últimas líneas son trazos imaginarios que constituyen los círculos que pasan por los polos. Desde esta perspectiva, la otra medida: longitud, tiene su meridiano cero, acordado, a finales del siglo XIX, para evitar problemas cartográficos y prácticos y para contar los grados de longitud geográfica de cada lugar de la Tierra. Conviene anotar, dentro del ejemplo de medida y de línea, que un instrumento lineal práctico, tanto para la ciencia como para la vida cotidiana: el metro, propuesto originariamente como la diezmillonésima parte del cuadrante del meridiano terrestre y medido, actualmente, con mayor precisión desde la física, constituye la "unidad básica de la magnitud física que expresa la distancia entre dos puntos"; esta definición también se ajusta a la línea sencilla.

geométricos y propuso el Sol como centro del Universo. Más tarde Hiparco (siglo II a.C.) mostró su modelo basado en esferas, contemplando cinco de los planetas conocidos hoy en día más la Luna y el Sol. Ptolomeo volvió sobre la idea de la Tierra como centro del Universo y tuvieron que pasar varios siglos hasta que Copérnico (siglo XVI) le dio un vuelco contundente a la astronomía con la teoría heliocentrista y la mirada retrospectiva a los antiguas concepciones griegas. Esta teoría cobró un vigor inusitado con los planteamientos de Kepler sobre las órbitas elípticas de los planetas. 
Aunque la Tierra no es una esfera magnífica, como lo demostró Newton, el hombre siempre sueña con un globo perfecto, como lo plantearon los matemáticos griegos y como aparecía en el Timeo de Platón, en el cual: "todos los puntos de la superficie equidistan del centro", en una órbita quimérica que Borges plasmó en su fábula La esfera de Pascal, relato en el que se muestra, en unas pocas líneas, la concepción maravillosa de esta figura, partiendo de la premisa: "Dios es una esfera inteligible, cuyo centro está en todas partes y su circunferencia en ninguna"; una metáfora que encogía al escritor argentino y que lo llevó a entretenerse en la recreación geométrica y poética de narraciones variadas. Después de describir las maravillas de las líneas circulares, se entretiene en la divinidad y remata la descripción con una reflexión terrible, la misma a la que llegó Pascal:

En aquel siglo desanimado, el espacio absoluto que inspiró los hexámetros de Lucrecio, el espacio absoluto que había sido una liberación para Bruno, fue un laberinto y un abismo para Pascal. Éste aborrecía el universo y hubiera querido adorar a Dios, pero Dios, para él, era menos real que el aborrecido universo. Deploró que no hablara el firmamento, comparó nuestra vida con la de náufragos en una isla desierta. Sintió el peso incesante del mundo físico, sintió vértigo, miedo y soledad, y los puso en otras palabras: "La naturaleza es una esfera infinita, cuyo centro está en todas partes y la circunferencia en ninguna". Así publica Brunschvicg el texto, pero la edición crítica de Tourneur (París, 1941), que reproduce las tachaduras y vacilaciones del manuscrito, revela que Pascal empezó a escribir effroyable: "Una esfera espantosa, cuyo centro está en todas partes y la circunferencia en ninguna" (Borges, 1985, p. 201).
Un caso similar a la concepción borgiana sobre la esfera ocurre al tratar de encontrar una definición de las "líneas de investigación"; se sabe que existen, por lo menos se tiene la conciencia de que son un constructo mental que sirve para plasmar sobre un papel u otro material una concepción de longitud, espacial, figurativa, corporal, de un ser, una cosa, un mundo o un universo. Líneas que se transforman en un elemento intangible, que trata de justificarse a través de proyectos, grupos y personas que las conforman y les dan sentido.

Tomar como referente la esfera para buscar un centro y unos puntos equidistantes, en la concepción de línea investigativa, bien puede ser una forma de llegar a una definición, aunque ésta trate de escaparse como el "centro que está en todas partes" y su circunferencia "en ninguna".

\section{NARRATIVA Y LÍNEAS}

Guillermo Martínez, narrador y matemático, en una serie de artículos, efectúa un análisis minucioso de la obra de Borges y muestra, a través de diversos ejemplos, la esencia de los tratamientos verbales y conceptuales borgianos que desembocan en un universo detallado, lleno de formas, figuras, fondos y trasfondos que no pueden escapar de la geometría, del laberinto, la línea y el punto, ni de los elementos y personajes que precedieron su obra: los argumentos euclidianos, los teoremas, Pitágoras y Poe, Pascal, Fermat, en fin. Martínez se detiene en los relatos que corroboran no sólo el pensamiento, sino también el ejercicio matemático, exactamente como lo ve Borges y como éste los traslapa y los recrea desde otros geómetras y artistas: 
Pensemos en el matemático que tiene que probar por primera vez un teorema, no en el matemático que sigue línea por línea la demostración de un teorema ya probado (que sería algo así como el lector con respecto a la obra ya terminada) sino en el matemático que se propone demostrar un resultado y no sabe ni siquiera si esa demostración verdaderamente existe. Esa persona se maneja en un mundo a tientas, y tiene que ir probando y equivocándose, refinando su hipótesis, volviendo al principio para intentar otro camino. Tiene, también todas las infinitas posibilidades a su alcance y a cada paso (Martínez, 2005, p. 56).

Al analizar esta deducción de Martínez, se puede hacer una abstracción y pensar que se está leyendo un cuento o un poema de Borges y el desarrollo de su lógica, su imaginación y su estética. Como cada persona construye su propio mapa del mundo, que lo rodea y elabora infinitas relaciones para interpretar la realidad -su realidad- y tratar de explicar el mundo a los otros, bien se puede decir que el universo de Borges estaba plasmado de referentes geométricos; por ejemplo, del laberinto, uno de sus más osados símbolos, una constante de su construcción literaria y una metáfora de su conocimiento. Sus poemas y sus cuentos aluden contantemente a esta figura mítica.

La leyenda griega que da trasfondo a la concepción borgiana cuenta que Dédalo, un inventor griego, constructor de palacios y un personaje al que consultaban los dioses y los hombres fue el encargado de hacer una obra compleja con múltiples cuadrados y círculos, con pasadizos sin salida, en una intrincada confluencia de líneas para albergar al monstruoso Minotauro, fruto de los amores clandestinos de Pasifae con el el toro de Creta. Minos, esposo de la reina infiel, ordenó a Dédalo que hiciera el palacio y éste tuvo que obedecer. No en vano Dédalo, el forjador griego, simboliza la ingeniosidad, la constancia, la búsqueda, el método del investigador incansable que persigue su propósito hasta alcanzarlo eliminando las posibles adversidades. En el relato mítico del laberinto se encuentra el culmen de las líneas rectas y curvas, la construcción y el desenredo de los enigmas que agobian el conocimiento humano. Simbólicamente, la maraña de pasadizos y calles infinitas, de intrincadas confluencias de líneas, significa los múltiples vericuetos en los que el científico o el artista se introducen para explicar el mundo o, por lo menos, tratar de interpretarlo y de expresarlo.

La amalgama de líneas y las construcciones laberínticas son una constante en la ciencia y en el arte. Por ejemplo, Borges, en La casa de Asterión, describe el laberinto infinito del Minotauro sin líneas ni curvas, sin muebles, sin principio ni fin: "Todas las partes de la casa están muchas veces, cualquier lugar es otro lugar" (Borges, 1996, p. 71): un laberinto magistral, infinito, como el conocimiento, la ciencia y la investigación, como el amor, otro trasfondo de la obsesión de sus escritos. El laberinto borgiano, en toda su poética, simboliza la construcción perfecta, similar a la biblioteca que puede albergar todo el saber y el sentir, probablemente en una palabra. Su cuento, Los dos reyes y los dos laberintos, muestra el laberinto construido por el hombre en contraposición con el laberinto construido por la divinidad sin "puertas que forzar, ni fatigosas galerías que recorrer, ni muros que veden el paso" (Borges, 1996, p. 140). En El jardín de senderos que se bifurcan, el laberinto va más allá de la confluencia de líneas y espacios, haciendo converger el tiempo: “Un laberinto de símbolos -corrigió-. Un invisible laberinto de tiempo" (Borges, 1972, p. 83). 
También en sus poemas Laberinto y El laberinto se aprecia la concepción del conocimiento que juega con la geometría y se pone al alcance de la mano pero, a su vez, es inaccesible, rondando el tiempo, el mito, sus más profundas convicciones: las "redes de piedra que me cercan", en las "Rectas galerías que se curvan en círculos secretos al cabo de los años" (Borges, 1985, p. 24).

La línea argumental en el autor argentino se convierte no sólo en un trazo formal, sino también en una trama conceptual. Sus escritos no transitan en línea recta, por el contrario, van y vuelven; quizás, la figura que mejor define su narrativa es el laberinto, el artificio de encrucijadas que, paradójicamente, tiene múltiples salidas. El culmen del acceso al conocimiento, con las infinitas vueltas y revueltas de sus líneas espaciotemporales, se ve en toda su obra y se puede apreciar plenamente en la primera estrofa de su poema El Laberinto:

No habrá nunca una puerta. Estás adentro

Y el alcázar abarca el universo

$Y$ no tiene ni anverso ni reverso

$\mathrm{Ni}$ externo muro ni secreto centro (Borges, 1985, p. 25).

Definitivamente, las líneas marcan un derrotero en la narrativa y en el proceso investigativo, en la búsqueda de la verdad científica, estética y cotidiana. Las líneas constituyen un faro, a veces un laberinto, una encrucijada que envuelve, en el caso de Borges, su vida y su obra, en el caso de un investigador cualquiera, su proyecto y su horizonte.

\section{LÍNEAS Y PROBLEMAS}

Carl Sagan y Ann Druyan en un hermoso, sencillo y accesible producto científico: Sombras de antepasados olvidados, muestran la intrincada forma de respuesta a los enigmas que plantea el medio, desde la contestación que dan los sencillos animales unicelulares hasta la réplica de la especie más evolucionada. El ser humano, en su esencia básica, es el único animal capaz de crear problemas, de enfrentarlos, de descubrir nuevas alternativas y de proponer diversas soluciones, a veces no creativas, sino destructivas. Estos cuestionamientos fácilmente se encuentran en cualquier esquina de nuestras ciudades: ¿por qué agredimos a nuestros semejantes? ¿Por qué tratamos de violentar a un jugador de un equipo contrario al de nuestro interés? $\mathrm{O}$ ¿por qué somos condescendientes con alguien que vulnera nuestros más íntimos deseos? Estos interrogantes se constituyen en razones de vida y en problemas que merecen ser estudiados:

La agresión es adaptativa... ¿a qué se debe que los machos sean tan a menudo más agresivos que las hembras? $\mathrm{Si}$ las hembras generaran algo menos de estrógeno y algo más de testosterona ¿no podrían resultar tan agresivas como los machos? Existe una especie de igualdad entre los sexos para la agresión en los lobos, las ardillas arbóreas, los ratones de laboratorio y las ratas, las musarañas de cola corta, los lémures de cola anillada y los gibones... El hecho evidente de que los machos de la especie humana sean más agresivos que las hembras (la testosterona del plasma sanguíneo es unas diez veces más abundante en hombres que en mujeres) no obliga en absoluto a aplicar el sistema en el resto del reino animal, ni siquiera en el resto de los primates (Druyan \& Sagan, 1998, p. 221). 
Con su acierto característico, el doctor Mario Bunge ${ }^{7}$, en su libro La investigación científica, manifiesta que la capacidad de "ver nuevos problemas y de inventarlos" es una característica del ser humano y de su papel como científico o investigador:

Cuanto más rentables son los problemas descubiertos, planteados y resueltos por un investigador, tanto mayor es la valía de éste. No hace falta que los resuelva todos: basta con que suministre -directa o indirectamente- a otros investigadores problemas cuya solución puede constituir un progreso relevante del conocimiento. Esto debe subrayarse en una época en la cual el descubrimiento de problemas se descuida en favor de la resolución de problemas (Bunge, 2000, p. 145).

Un investigador no puede apartar su mira de las líneas de conocimiento e investigación que se abren a sus inquietudes y cuestionamientos. La línea permite el trazo o viceversa y en un planteamiento dialéctico engarza al problema, lo plantea y brinda alternativas o posibilidades de acceso a su solución. Siguiendo con Bunge: "la selección del pro-

7 El investigador Mario Augusto Bunge, amante del conocimiento, la investigación y la escritura cientíica, se considera como uno de los pensadores actuales más influyentes en el marco de la filosofía de la ciencia. Sus aportes a la concepción del método y del problema como elementos primordiales del conocimiento son fundamentales en cualquier trabajo investigativo. Su manual sobre La ciencia, su método y su filosofía (1960) sigue siendo un punto necesario de reflexión. Su "realismo científico" lo ha llevado a planteamientos que se oponen a las posiciones conceptuales como el Psicoanálisis, la hermenéutica y la misma fenomenología, entre otras. Presenta una obra extensa que conviene indagar detalladamente: Tratado de filosofía; Diccionario de filosofía; La investigación científica. Su estrategia y su filosofía; Ser, saber, hacer; A la caza de la realidad. La controversia sobre el realismo, entre otras. Su concepción sobre la realidad, el mundo y la ciencia bien se puede sintetizar en una frase de su anexo a la obra Ciencia, técnica y desarrollo: "La ciencia sólo puede florecer cuando queda tiempo para pensar en problemas que no se refieren a las necesidades inmediatas; por esto ella no existe en las regiones 0 los periodos en que dichas necesidades inmediatas no son satisfechas" (Bunge, 1998, p. 210). blema coincide con la selección de la línea, puesto que investigar es investigar problemas" (Bunge, 2000, p. 147). Acudir a este planteamiento es volver los ojos a un debate permanente que hace repensar la "utilidad" y su contrario "la no utilidad" de una línea. Esencialmente no se puede llevar al grupo o equipo investigador a una problemática acientífica, es decir, a solucionar problemas con un interés particular, ya sea económico, político, artístico u otro, omitiendo la esencia prospectiva y la razón de ser.

Lo anterior no se opone, de manera alguna, al planteamiento de problemas del diario vivir, por el contrario, un punto sencillo origina una línea, una red o un garabato, un proyecto complejo o una suma de proyectos, un trabajo diario pedagógico investigativo o una elemental elucubración.

\section{LOS OBJETOS Y LAS LÍNEAS}

Realizar un debate sobre la definición de un objeto es una tarea compleja; no obstante, en la construcción de una línea de conocimiento o de investigación es determinante precisar su esencia y sus alcances. Un objeto remite a una entidad susceptible de generar un problema, originar un marco de estudio y abrir múltiples posibilidades de acción e interacción.

La misma etimología del término connota "poner delante" y exactamente estas palabras definen al objeto, aquello que el sujeto tiene frente a sí y trata de conocer. En el ámbito epistemológico se puede hablar de un objeto material y de uno formal, lo cual traza una discusión entre "lo conocido y el objeto de conocimiento" $y$, naturalmente, abre el debate científico entre la subjetividad y la objetividad, entre la posibilidad de acercar- 
se o no a lo analizado y de inmiscuirse o no en lo investigado. Sin entrar en mayores disquisiciones, para no alejarse de la temática, pero dejando abierta la puerta discursiva, siguiendo a Kant, se puede afirmar que el objeto es aquello que no reside en el sujeto, pero que puede ser aprehendido:

\begin{abstract}
Existen cuatro operaciones mentales básicas en la aprehensión de un objeto o en la comprensión de la realidad: relación, selección, reacción y grabación, las cuales no se presentan, estrictamente, de una manera secuencial. Pues bien, el nexo del hombre con la naturaleza también se puede plantear a nivel de recolección de información, organización y deducción (Parra, 2003, p. 28).
\end{abstract}

Desde esta perspectiva, las operaciones mentales determinan que un objeto o un conjunto de objetos se puedan abstraer y se conviertan en un material que da horizonte a la línea. Teniendo en cuenta que el primer elemento que surge en el conocimiento es el objeto, su definición dentro de la línea aclara el panorama y hace que se visualice la comprensión de la realidad.

En los diferentes campos del saber, el objeto se convierte en el eje sobre el cual se manifiesta un sistema. En la llamada programación orientada a objetos (POO), éstos se definen en "términos de tiempo de ejecución en los cuales se realizan tareas".

En el lenguaje matemático, el objeto hace referencia a un ente abstracto, susceptible de ser estudiado. En el ámbito literario y en el lenguaje estético, el objeto tiene unas características especiales, las cuales, a su vez, también conllevan la abstracción. Estos planteamientos hacen pensar que el objeto es determinante para fijar el punto de partida de la línea y, dialécticamente, su pun- to de llegada. Por extensión, bien se puede precisar que tanto en las ciencias como en los lenguajes, estrictamente no científicos, es perentorio fijar un objeto de conocimiento, estudio o investigación que sustenten el trazo de la línea, el horizonte.

Luis Buñuel, considerado como uno de los grandes genios del siglo XX, con obras de gran impacto como Un perro andaluz (1929), La edad de oro (1930), Los olvidados (1950), Él (1952), Viridiana (1961) y El fantasma de la libertad (1974), entre otras películas, marcó una época de rebeldía, surrealismo y denuncia social. Buñuel sintetizó en su película magistral Ese oscuro objeto del deseo (1977) una serie casi infinita de posibilidades y de artilugios que se pueden presentar en la consecución de algo que se persigue, de una meta, de un ideal, de un objeto. El argumento toma como pretexto el sexo, pero va más allá al plantearle al espectador la búsqueda de algo difícil e, irónicamente, fácil de conseguir. En el desarrollo temático se juega con la búsqueda, con un camino que pretende superar los obstáculos y se adentra en los vericuetos del riesgo, el encuentro, el placer, la interacción, la cercanía y el alejamiento, la realidad y la ficción. Es un ejemplo de un juego que busca llegar satisfactoriamente al final, a la consecución del objeto que, fácilmente puede deslizarse entre los dedos. De una manera similar, el proyecto investigativo presenta avatares, combinaciones e interacciones diversas que conllevan la aprehensión del objeto.

\section{LÍNEAS E INSTITUCIÓN}

Un investigador bien puede moverse en el campo de su profesión interrogándose sencillamente por qué su discípulo no estudia, qué elementos hacen que no lea su 
ciencia, su profesión, lo que le rodea, que no visualice un horizonte y se quede en un presente, probablemente placentero, pero inocuo. O puede también preguntarse, cómo podría plantear mejores formas de acercamiento al saber e inclusive nuevas maneras de aproximación a éste y, en el mejor de los casos, producir conocimiento, brindar diferentes caminos conducentes al encuentro de la verdad. El trabajo investigativo constantemente vuelve sus ojos a los enigmas clásicos: qué somos, qué hacemos y para dónde vamos y propugna por soluciones novedosas, por la visualización de diversas relaciones y conexiones, sin dejar de lado el abordaje de problemas nuevos, bordeando siempre una línea que delimita el horizonte y hace vislumbrar una respuesta.

Aristóteles, punto de mira obligado para científicos y filósofos, trazó el confín de la investigación occidental, reflexionando sobre una verdad palpable y sensible a cada hombre: nacer, crecer, reproducirse y morir, es decir, los seres cambian, incluyendo los seres inanimados, los cuales, por lo menos varían en la forma. Pero, más allá del plano de los hombres y las cosas -dice el estagirita-, en otro nivel se encuentran los planetas y la luna, las estrellas fijas y el motor que mueve todo el universo. Unos investigadores se quedan en el primer plano y abordan los cuestionamientos, sin mayor preocupación o con una inquietud básica: una piedra cae, porque sí, porque es pesada, porque se desprendió de algún sitio, porque debe caer; alguien más avezado diría que cae porque existe una ley que la hace caer. Los problemas y los planteamientos se quedan en un nivel que tiene una lógica y un sentido que llega a ser absolutamente explicativo del mundo, un sentido que guía la superviven- cia, la reflexión, pensar y discurrir, inclusive marca el acontecer del ser humano y su convivencia. Otros investigadores se introducen en el segundo plano, el mismo que, desde los aristotélicos, sería el supralunar, aquél en el cual los cuerpos celestes giran sin parar y que presenta unas leyes que necesariamente influyen en el devenir. Puesto que "el hombre es un animal racional" (Hischerberger, 1977 p. 49) y que el pensamiento occidental se casó con esta premisa aristotélica, se puede afirmar que nadie puede negar que la explicación de los fenómenos se puede dar $\mathrm{y}$, de hecho, se ha dado a través de la argumentación filosófica (primer plano investigativo).

Muchos siglos pasaron para que en la búsqueda de la verdad intervinieran unos seres que trataron de explicar los fenómenos que ocurrían a su alrededor y más allá a través de experimentos (segundo plano investigativo) sobre los cuales se tenían algunas formas de control. Investigadores que demostraron que existían leyes que explicaban y relacionaban la simple caída de una piedra con la rotación de un planeta (Newton), las magnitudes y las leyes universales de la gravitación (Kepler), la ley del péndulo y sus sistema de análisis experimental (Galileo), la relatividad espacio-temporal (Einstein) o el enigma del universo que lo mismo puede estar en un hueco negro que en una cáscara de nuez (Hawking). Si se quisiera profundizar, fácilmente se puede hallar que tanto para el primer plano investigativo como para el segundo existe un elemento primigenio: la línea, la cual determina el primer nivel, mítico, referencial, el de los hombres y las cosas, la misma que en el segundo plano, el supralunar, lleva a las leyes. 
La investigación, al estar vinculada ineludiblemente a la docencia, supone, contrario a los postulados científicos que velan por la independencia del objeto investigado, una interdependencia que puede quitarle cientificidad al proceso. No obstante lo anterior, la institución, como organización rectora del proceso, receptora de éste e impulsadora del producto, fuente de recreación, socialización y difusión del conocimiento, tiene como uno de sus papeles, velar porque el hecho investigativo constituya una interacción entre el docente y el estudiante, entre los docentes, entre los estudiantes y entre toda la comunidad educativa con su contexto. Así se generan investigadores, semilleros, grupos y centros interesados en identificar el objeto de su estudio, de su investigación, de develar problemáticas conducentes a la transformación social desde los ámbitos científicos y artísticos, disciplinares, transdisciplinares e interdisciplinares.

Introducir el término problema supone una sinergia interna, la cual, a su vez, se refiere a los intereses y a la manera como cada uno de los investigadores se deja interpelar por la realidad, realizando una conexión interna que precipita un planteamiento, un cuestionamiento e inquiere una respuesta (Parra, 2005).

La escuela básica, tanto como la universidad, tienen la obligación de proponer las líneas de conocimiento e investigación en cada plano pertinente enfrentando los problemas que a diario surgen en el transcurrir, en la vivencia y en el ámbito disciplinar, transdisciplinar y profesional. Las líneas de investigación constituyen una conceptualización particular y un punto de referencia obligado. Al construirse y reconstruirse permanentemente, a partir del planteamiento básico fundamental que se enriquece con los procesos investigativos, con las demandas y necesidades del contexto, con el desarrollo e implementación de los proyectos que dan respuesta a los problemas y originan nuevos problemas y nuevos retos, adquieren una característica especial que le da su sentido disciplinar y trandisciplinar (Parra, 2005, p. 82).

Las líneas de investigación giran en torno a un eje que da la institución y el contexto; generalmente, arraigadas en el currículo, tienden a ser de dos clases: unas que conforman la estructura nuclear y otras que son activas o prácticas. Las primeras representan la identificación problemática y su marco conceptual y las otras hacen experiencial la identificación y facultan la organización, planificación y abordaje del problema. Desde esta perspectiva, el primer agente que se involucra en la definición y el trazo de la línea nuclear, institucional o paradigmática es el observador, seleccionador o identificador del problema, ya sea el niño ingenuo, el estudiante consagrado, el docente inquieto, el investigador dedicado, el científico, el artista, en suma, los intervinientes en el proyecto, quienes sugieren e identifican el problema. El segundo agente determinador está dado por la interacción entre los debates, el diseño mismo de los proyectos, las discusiones, los presupuestos curriculares, los planes de estudio y las reflexiones temáticas, las experiencias didácticas y los cuestionamientos en el proceso de enseñanza-aprendizaje. El tercer elemento clave en la definición lo constituye la tradición y la experiencia acumulada de conocimiento. El último elemento que determina la línea institucional o nuclear lo da el contexto, el medio, la necesidad o el fenómeno que suscita el problema. 
Por su lado las líneas activas o prácticas constituyen la puesta en marcha de los postulados generales que dan las líneas nucleares o estructurales ${ }^{8}$. En este plano, las líneas hacen real el problema y brindan los elementos para su solución a través de la conformación de grupos, del trabajo individual, de la ejecución de los proyectos, de su seguimiento y evaluación, de la concreción temática, de la fijación disciplinar o interdisciplinar de una problemática.

\section{Epílogo. LA LÍNEA, FUNDAMENTO DE LO EXISTENTE}

Tal y como se puede apreciar, la línea es el elemento primordial del conocimiento y constituye el punto de partida, en su modo más simple y, paradójicamente, en su forma más compleja, debido a sus múltiples posibilidades de construcción. De la misma manera como lo plantearon los matemáticos griegos y lo enseñaron las culturas orientales, también lo bosqueja la narrativa borgiana, en un poema que sintetiza la esencia de

8 Dado que la concepción de líneas sugiere un problema susceptible de ser investigado a partir de un diagnóstico, de la búsqueda documental, de la experiencia investigativa institucional, de las sugerencias del contexto (necesidades, problemas, temas de investigación) de las discusiones y criterios de los investigadores, en la Universidad Santo Tomás de Bogotá, Colombia, se trabajó un proyecto que configurara un modelo para la investigación institucional (Parra, 1985). A través de una serie de talleres sobre problemas regionales y líneas se obtuvo un producto: "Modelo para la investigación institucional" que contemplaba los dominios, programas, proyectos y líneas que enmarcaban el trabajo investigativo en la institución (Arias, 1995). En el año 2000 se configuró un segundo proyecto: Proyecto investigativo institucional que contempló las líneas como un resultado de la suma de proyectos, originados a partir de problemas dados por el contexto y por las particularidades curriculares (Parra, 2000). Posteriormente se trató de diferenciar entre las líneas sustantivas institucionales y las líneas prácticas, particulares de cada programa, cuyos aspectos conceptuales se definen a partir de cátedras institucionales, las cuales comprenden los componentes académicos, de extensión y de investigación, 10 mismo que la tradición de conocimiento de la Universidad y de la Comunidad de Padres Dominicos (Parra, 2005). la línea, a través del amor, lo cósmico, las cosas existentes, más allá del arte, la matemática y la imaginación, en un juego simbólico y cognitivo; todo el ámbito de "El enamorado" constituye un resumen perenne que describe las líneas en su esencia, en el siguiente fragmento poético:

Lunas, marfiles, instrumentos, rosas, Lámparas y la línea de Durero,

Las nueve cifras y el cambiante cero, Debo fingir que existen esas cosas (Borges, 1997, p. 51).

Como se puede observar, hasta este punto del desarrollo conceptual, llegar a una definición de línea es una tarea compleja que contempla desde su primera acepción mítica, el simple trazo que comunica al ser humano con lo trascendente hasta su designación como sucesión continua e indefinida de puntos. Adentrarse en el universo de los puntos significa posar la mirada en un horizonte geométrico, en el cual la construcción de los diferentes elementos lanza al investigador al análisis de las diversas propiedades y medidas espaciales, al cálculo y planteamiento de problemas, a la edificación de lenguajes explicativos del mundo, por ejemplo, la representación o proyección de figuras sobre un plano, como la esfera, "cuyos puntos equidistan de otro llamado centro".

Irrumpir en los fundamentos cognitivos denota un investigador que quiere explicar el fenómeno investigativo, en este caso un referente básico: la línea, una manifestación que aparece como objeto de estudio y de "experiencia sensible" (Kant). La narrativa, el hecho de contar, connatural al hombre, da visos sobre la explicación, la concepción y la definición de línea; desde esta perspectiva, el reto de un escritor, un científico o un in- 
vestigador cualquiera es mostrar lo investigado, describir el fenómeno y para ello debe apuntar a lo que puede ser materia sensible o cognitiva, aquello susceptible de ser examinado: el objeto. La búsqueda incansable del ser humano por explicar la realidad lo hace incursionar en el campo científico, estético y cotidiano, lo que lo lleva a sortear múltiples dificultades y a visualizar distintos problemas, dentro de los cuales, el investigador, el grupo y la institución constituyen elementos determinantes en la construcción de las líneas y en la precisión de su objeto de estudio.

$\mathrm{Al}$ asimilar la estructura lineal con la unión de puntos, se puede hacer un símil natural con la conjunción de proyectos, grupos y procesos. Siendo así, la línea como punto de partida adquiere unas características que le son propias: estable y dinámica, unificadora y divisora, generadora y condensadora.

La cualidad de estable hace que la línea con vida propia tenga un equilibrio y una representación exacta, significativa, directiva, capaz de conducir y mantener un proceso cognitivo e investigativo. Dinámica, en cuanto no está solamente suspendida en un plano, sino que posee la potencialidad de transformación, de proyección, ya sea hacia el trazado figurativo o corporal. Unificadora, porque en ella confluyen las distintas propuestas, perspectivas, puntos, equipos, trabajos. Divisora, en el sentido de estar en un borde disciplinario y establecer los papeles que se desempeñan dentro de uno y otro plano sin que separe y aísle en el sentido estricto -salvo que sea necesario-. Si esto es así, se puede hablar de líneas que dan pauta para un trabajo disciplinar, multidisciplinar e interdisciplinar.
La esencia de la línea viene dada por su orientación, su campo de acción, su capacidad de adaptación y transformación, la definición de su objeto, y la precisión o conjunción del problema. Las diversas líneas que se pueden generar en el diario transcurrir, en el amplio campo de la ciencia y en el ámbito inagotable del arte, en la filosofía y la teología, en los antiguos postulados orientales y en las premisas occidentales, bien se pueden reducir, por una propuesta metodológica, en un espacio institucional a líneas básicas, medulares, estructurales, de referencia, similares a guardianes de la potencia aristotélica y a líneas que, dentro de esta misma perspectiva, se pueden volver acto, líneas activas o particulares.

Más allá de las elucubraciones que harían de la concepción, de la clasificación y del referente de líneas una larga lista, podemos detenernos en las líneas figurativas, en las que conforman el arte y la ciencia, en las que marcan el diario devenir y en las líneas del conocimiento y de la investigación. Atrás han quedado los investigadores encerrados en un castillo inexpugnable, afiliados a grupos herméticos tras una verdad esquiva. Los académicos dedicados y los ratones juiciosos de biblioteca dan paso a los investigadores inquietos que buscan en las autopistas digitales y trabajan "en línea" las respuestas a los cuestionamientos infinitos que aquejan al hombre. Las redes, conformadas por líneas múltiples, por inacabables maneras de respuesta, quieren dar un sentido a la ciencia, al arte, al simple trajinar del ser humano, a veces con desvíos caprichosos y otras tantas con metas precisas. Es posible que en el laberinto inagotable del conocimiento se pueda hallar lo que se busca, la línea está ahí, como estructura, fundamento, medio, esencia o, simplemente, como horizonte. 


\section{REFERENCIAS}

Arias A., A. (1995). Modelo para la investigación institucional. Bogotá: Universidad Santo Tomás.

Borges, J.L. (1972). Ficciones. Barcelona: Círculo de lectores.

Borges, J.L. (1985). Nueva antología personal. Barcelona: Bruguera.

Borges, J.L. (1996). El Aleph. Madrid: Alianza.

Borges J.L. El otro, el mismo. Recuperado el 18 de enero de 2009 de: www.literatura. us/borges/elotro.html-95k

Borges, J.L. (1997). Historia de la noche. Buenos Aires: Emecé.

Bunge, M. (1998). Ciencia, técnica y desarrollo. México: Hermes.

Bunge, M. \& Sacristán, M. (2000). La investigación cientifica: Su estrategia y su filosofía. Filosofía. México: Siglo XXI.

Druyan A. \& Sagan, C. (1998). Sombras de antepasados olvidados. Bogotá: Planeta.

Eco, U. (1994). La búsqueda de la lengua perfecta (M. Pons, trad.). Barcelona: Crítica.
Hathaway, N. (2008). El universo para curiosos. Barcelona: Crítica.

Hirschberger, J. (1977). Breve historia de la filosofía. Barcelona: Herder.

Hoddinott, B. (2007). Dibujo para Dummies. Bogotá: Norma.

Kandinsky, V.V. (1994). Punto y línea sobre el plano. Barcelona: Labor.

Martínez, G. (2005). Borges y la matemática. Buenos Aires: Eudeba. Universidad de Buenos Aires.

Marchese, A. \& Forradellas, J. (1994). Diccionario de retórica, crítica y terminología literaria. Barcelona: Ariel.

Parra R., O. (2003). Pensar y soñar. Avances en enfermería, 24-31.

Parra R., O. (2005). Proyecto investigativo institucional. Proin. Un enfoque para la concepción y el desarrollo de la investigación. Bogotá: Universidad Santo Tomás.

Restrepo G., B. (1997). Investigación en educación. Bogotá: Icfes, Ascun.

Wilhem, R. (1982). I Ching. El libro de las mutaciones. Barcelona: Hispano Americana. 